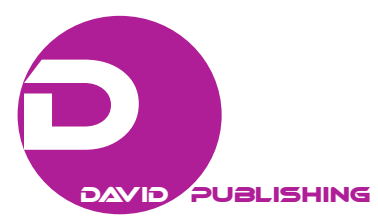

\title{
Explaining Customer Experience of Digital Financial Advice
}

\author{
Diederick Van Thiel \\ AdviceRobo, London, UK \\ Fred Van Raaij \\ Tilburg University, Tilburg, The Netherlands
}

\begin{abstract}
The goal of this paper is to analyze the customer experience of digital-driven financial advice systems. It is the objective of this study to develop a cross-cultural model for validating customer experiences of digital financial advice. In doing so, both objective and subjective system aspects have been considered. It is found that experiential subjective system aspects are the most important. Surveys have been conducted in The United Kingdom and The Netherlands. In exploratory factor analysis, five dominant factors were obtained in the UK and six factors in The Netherlands to explain customer experience. Based on the factor scores, multiple regression analysis has been performed to develop the digital customer experience model (DCX model). This is the first cross-cultural model to evaluate customer experience of financial advice. In an era in which financial institutions and FinTech companies battle for the engagement of customers, the DCX model is the first to fundamentally drive value creation, differentiation, regulation, and future research.
\end{abstract}

Keywords: digital advice, robo advice, service quality, customer experience, financial advice

\section{Introduction}

\section{The Financial Advisor Is Dead}

Financial advice is badly needed for many consumers, as their financial litarcy is generally low (Van Raaij, 2016). This financial advice can be given in face-to-face contacts or in a digital way. Intelligent agents can be useful as digital assistants (Van Thiel, Goedee, \& Reijnders, 2008). The trend in the financial technology (FinTech) community points to the death of the financial advisor. People globally will soon be dealing with a robot for their financial affairs (Dunbar, 2016). Indeed, the University of Oxford University places financial advisors on their list of the "Top five jobs that robots are already taking” (Frey \& Osborne, 2015). Frey and Osborne's (2015) research indicates that financial analysts and advisors are being replaced by robo-advisors, driven by predictive systems, big data, and computing power.

\section{The Market of Robo-advice}

Currently, across many geographies, an increasing number of financial service providers are operating or considering the use of robo-advisors; online advice platforms that provide advice by complex computer algorithms (Bradbury, 2014). These robo-advisors make use of the increasing amount of behavioral data and

Diederick Van Thiel, M.S., Behavioural Science in Digital \& Robo-Advice, AdviceRobo, London, UK.

Fred Van Raaij, professor of economic psychology at Tilburg University, Tilburg, The Netherlands.

Correspondence concerning this article should be addressed to Diederick Van Thiel, AdviceGames, One Canada Square, Canary Wharf, London, UK. 
apply algorithms that match consumers or small business with financial products or portfolios. Examples are investment brokers, such as Betterment, Wealthfront, and Nutmeg that optimize personal investment portfolios. Lend Up, Kreditech, and eyeOpen connect borrowers to loans, and platform lenders such as Zopa or Funding Circle connect savers to borrowers. Furthermore, established traditional advice firms have introduced robo-advisors. Vanguard and Schwab introduced a free robo-service in addition to their offline advice, and they are growing faster than the internet-only robo-advisors. Fidelity offers robo-advice to customers making use of the Betterment platform. Intermediaries like Learnvest, Money Supermarket, and Eye Open also introduced robo-related services. However, further growth of robo-advice services is expected. Research agency AT Kearny predicted robo-advisors will run $\$ 2.2$ trillion in assets in 2020 because of the fast growing adoption rate of this service model among young generations.

\section{The Market of Digital Financial Services}

Financial decision making and thus traditional financial advice are being transformed by digitalization (R. Malhotra \& D. K. Malhotra, 2006). Financial advice is defined as the third-party services that help consumers reach financial decisions (Collins, 2010). As consumers are getting more and more self-directed, financial capability building is becoming increasingly digital. Collins's (2010) review of financial advice models defines a model for financial capability building. The model contains three financial advice pillars describing the advisory service models in financial retail.

Pillar 1 contains all information models, like printed product information, tools, websites, comparison and recommendation sites, and workshops. The impact of digitalization on these information models is evident. The growth of price comparison websites like Money Supermarket, Compare the Market, and Money Savings Expert are only a few examples of the digital impact on information models.

Pillar 2 contains all advice models, Collins distinguished: (a) technical experts such as mortgage or financial planning advisors, (b) transactional agents who perform the same advising activities as technical experts, although they are tied to a brand, (c) counselors who work with people on their personal financial issues are often as a result of their financial illiteracy, and (d) financial coaches who focus on designing and realizing financial goals with their customers.

The growth of robo-advisors for investment firms such as Wealthfront, Betterment, FutureAdvisor, Learnvest, Nutmeg, and lending such as eyeOpen, Zopa, and Funding Circle shows the impact of digitalization on this advice pillar. Interestingly, the robo-investment advisors currently perform more like mechanism models, which have the objective of making consumer's financial decisions easier by automating intelligence. Future development of these models will be towards providing tailored personal behavioral and product advice and services (L’Hostis \& Ensor, 2015).

Pillar 3 contains mechanism models: (a) default (prediction) models, (b) automatic deposit models, and (c) product constraints models. Companies such as Creditkarma, Zestfinance, Ondeck, and AdviceRobo, actually all investment robo-advisors show that digitalization also impacts this mechanism advice pillar.

Robo-advisors are service models bringing easy-to-use, low-cost advice services. Therefore, they have the potential of reducing financial stress and improving financial security for mass consumers in both developed and developing countries. To be able to reach this potential, it is important to build superior customer experience to traditional bank digital environments for many people. Customer experience is the internal and subjective response that customers have any direct or indirect contact with a company (Van Thiel, 2009; 
Verhoef, Lemon, Parasuraman, Roggeveen, Tsiros, \& Schlesinger, 2009). Because customer experience is important for the future adoption of robo-advisors and no research has been done on this topic so far, the scope of this paper is on explaining the customer experience of digital advice models as described in Pillar 2. Driven by the complexity of financial advice (individual products vs. portfolios), digital advice in both lending and investment shows high thresholds. Because authors have lengthy experience in consumer lending, this research focuses on customer experiences of robo-advisors in the lending market. To understand and improve the customer experience, it is necessary to conduct empirical evaluations that consider the entire process of how the customer chooses and buys a mortgage. Therefore, the DCX model is the first to describe how objective aspects in the advice system are subjectively perceived by the customer and how these perceptions result in specific customer experience evaluation. Such a user-centric model will provide a deeper understanding of what parameters drive customer experience of digital financial advice systems, and what impact these parameters have on the actual customer experience. It also allows for a better understanding of how certain aspects of the digital financial advice systems result in a better customer experience, which helps further user-centric research and the development of robo-advisors.

\section{From Service Quality to Customer Experience}

\section{Service Quality}

Nelson (1970) classified products into search and experience goods. Search goods offer consumers the ability to obtain product quality information prior to purchase. Experience goods, like financial advice, are goods that cannot be inspected before purchase. Credence goods are a specific category of experience goods. Wolinsky (1995) defined credence goods as a specific category of experience goods. He defined credence goods as experience goods whose sellers are also the experts who determine the customers' needs. Insights from his research into competition of credence goods markets are that the information asymmetry in credence goods markets leads to prices that embody mark-ups over costs and that the equilibrium does not maximize expected customers' surplus. The third consequence of information asymmetry in credence goods is fraud (Wolinsky, 1995; Emons, 1997). Since customers can never be certain about the quality of sellers' services, experts have strong incentives to cheat. Financial advice is an example of a good driven by information asymmetry. However, several authors (e.g., Alba, Lynch, Weitz, Janiszewski, Lutz, Sawyer, \& Wood, 1997; Klein, 1998; Peterson, Balasubramanian, \& Bronnenberg, 1997) suggested that because the Internet enables consumers to learn from the experiences of others and to gather product information that is often difficult to obtain in offline settings (Klein, 1998; Lynch \& Ariely, 2000), it makes all attributes searchable and erases differences between the searching and the experience of goods.

Friends and family members, price comparison and recommendation systems provide value to financial customers by low cost, broad offering, and support in making financial decisions. Stigler (1961) introduced the concept of returns to information search. According to Stigler's (1961) analysis, consumers stop searching for information at the point when the marginal cost of additional searching (time, effort, and other resources) equals the marginal benefit. Less-experienced and less-educated consumers will have to work hard to find and assimilate information. Therefore, this relatively higher marginal cost of searching for information may result in less searching, overall. Nonetheless, all consumers, regardless of their experience and expertise, will cease searching for information when the marginal cost equals the marginal benefit, and hiring a financial advisor may lower the marginal cost of searching for information relative to searching on one's own. Regarding 
financial products, consumers find it is difficult to evaluate complex financial products offered, such as investments, life insurance, and mortgages, as their assessment requires domain knowledge and long-term vision. Therefore, financial advice is able to play an essential role in the retailing of financial products (Inderst \& Ottaviani, 2012).

A financial advisor may lower the marginal cost of searching for information by acquiring expertise on a relatively complex topic and then working with multiple clients, each of whom may only need the information once in a lifetime. The scarcity of scholarly research on the service quality of (digital) financial advice, calls for the development of a model to explain the customer experience of digital financial advice models based on adjacent research to service quality, user experience, and customer experience.

Earlier service quality models focus primarily on the gap between expected and perceived service quality. Grönroos (1984) already suggested that managing perceived service quality implies that the firm has to match the expected service and perceived service to each other to achieve consumer's satisfaction. Furthermore, he identified three components of service quality, namely: technical quality of what customers actually receive as a result of their interaction with the service firm; functional quality of how they actually get the outcome; and image as hedonic factors like tradition, ideology, word-of-mouth, or pricing. Later models (Parasuraman, Zeithaml, \& Berry, 1985; 1991; 1994; Cronin \& Taylor, 1992; Broderick \& Vichirapronpuk, 2002; Santos, 2003) built on this reveal that the service quality outcome and measurement are dependent on type of service setting, situation, time, and need factors. Furthermore, a customer's expectations toward particular services constantly change due to factors such as time, an increase in the number of encounters with a particular service, and a competitive environment (Seth \& Deshmukh, 2005).

\section{From Service Quality to User Experience}

With the development of human-computer services, service quality models evolved into human-computer interaction models on user and customer experience. User experience relates to their subjective evaluation of the interaction with a system (Knijnenburg, Willemsen, Ganter, Soncu, \& Newell, 2012). Knijnenburg et al.’s (2012) research to the user experience of recommender systems shows a historical trend in user experience on recommender system research. A significant part of the earlier research concerns creating and evaluating more effective prediction algorithms (Koren, 2010; Koren, Bell, \& Volinksy, 2009; McNee, Riedl, \& Konstan, 2006; Herlocker, Konstan, \& Tervee, 2004; Cosley, Lam, Albert, Konstan, \& Riedl, 2003). According to Knijnenburg et al. (2012), the premise of this algorithm research is that better algorithms lead to perceivably better recommendations. These improved recommendations, in turn, lead to better user experience in terms of choice, satisfaction, and perceived system effectiveness. For digital financial advice, this could imply that the advice quality would be the most important attribute of the customer experience.

$\mathrm{H}_{1}$ : The quality of the recommendation, or in the scope of this paper, advice quality is an important factor in explaining the customer experience of digital advice systems.

Furthermore, Knijnenburg et al. (2012) suggested other factors that influence the user experience of recommender systems (Pu, Chen, \& Hu, 2012; Konstan \& Riedl, 2012; Ozok, Fan, \& Norcio, 2010; Murray \& Haubl, 2009; McNee et al., 2006; Cosley et al., 2003). System aspects other than accuracy, situational, personal, and privacy concerns can influence system satisfaction (Knijnenburg, Willemsen, \& Kobsa, 2011; Knijnenburg \& Willemsen, 2009; Knijnenburg, Willemsen, \& Hirtbach, 2010; Komiak \& Benbasat, 2006; Teltzrow \& Kobsam, 2004). Knijnenburg et al. (2012) integrated these and other aspects into a user-centric framework for 
the evaluation of recommender systems. In their framework, the evaluation of the system is, just as in service quality models, driven by a user's perception of the system in terms of outcome-related, system-related, and process-related aspects. Furthermore, it is influenced by the objective effect of the system in terms of views, purchases, and usage. In the scope of this paper, actual quality of the financial advice should be a less important attribute of customer experience than attributes describing "the making of" the advice.

$\mathrm{H}_{2}$ : Both the system-related aspect and the process-related aspect of digital financial advice have impacts on customer experience outcome-related aspects such as the quality of the advice.

\section{From User Experience to Customer Experience}

Customer experience is strongly related to user experience, but it is holistic, rather than simply focusing on digital interactions. Verhoef et al. (2009) defined customer experience as originating from a set of interactions among a customer, a product, and a company or part of its organization, which provokes a reaction. This experience is strictly personal and implies a customer's involvement at different levels (rational, emotional, sensorial, physical, and spiritual) (Van Thiel, 2009; Gentile, Spiller, \& Noci, 2007, p. 397). Another and related definition is that:

Customer experience is the internal and subjective response customers have to any direct or indirect contact with a company. Direct contact generally occurs in the course of purchase, use, and service and is usually initiated by the customer. Indirect contact most often involves unplanned encounters with representatives of a company's products, service, or brands and takes the form of word-of-mouth recommendations or criticisms, advertising, news reports, reviews, and so forth. (Meyer \& Schwager, 2007, p. 118)

Adding to the above, Verhoef et al. (2009) argued that the customer experience construct is holistic in nature and involves a customer's cognitive, affective, emotional, social, and physical responses to the retailer. This experience is created, not only by those elements that the retailer can control (e.g., service interface, retail atmosphere, assortment, and price), but also by elements that are out of the retailer's control (e.g., influence of others, purpose of shopping). Additionally, Verhoef et al. (2009) stated that the customer experience encompasses the total experience, including the search, purchase, consumption, and after-sale phases of the experience. Therefore, it may involve multiple retail channels. As digital financial advice models will be both digital-only robo-advice systems and hybrid systems that combine both on- and off-line interactions, the holistic view on the total customer experience of information search, purchase, and after-sales are important to understand.

$\mathrm{H}_{3}$ : Holistic hedonic experiential aspects of the customer experience in digital financial advice models are more important than functional aspects.

\section{Developing the Digital Customer Experience (DCX) Model, Including Validation of Generalizability}

\section{Purpose of This Research}

The goal of this research is to provide a cross-cultural set of structurally related factors and their attributes that explain customer experience of digital financial advice systems. Customer experience and financial advice are ill-defined concepts, and lack well developed assessment methods and metrics. The influence of self-directedness on financial decision making increases because the Internet enables consumers to learn from the experiences of others and to gather product information. Therefore, it is the objective to develop a cross-cultural model for validating the customer experience of digital financial advice. In doing so, the study 
considers the impact of both objective and subjective system aspects.

The aim is to develop an easily applicable model for validating the customer experience of digital and hybrid financial advice systems. The research particularly identifies the explanatory factors and underlying attributes of customer experiences with digital financial advice. However, it also identifies the parameters of these factors and their functional or experiential nature. Having insight into the explanatory factors and their attributes and parameters, this paper aims to validate the stated hypotheses.

\section{Developing and Piloting the DCX Model}

As banks, financial advisors, and robo-advisors are more focused on customer centricity, this research's objective is to support improved understanding of the customer experience of user-centric digital financial advice models. The model is an objective validation instrument of customer experiences of digital financial advice brands. Therefore, it can help digital financial advisors to build deeper customer centric advice relations and better support differentiation with their advice systems. The model can also inspire researchers toward future digital advice systems.

To develop and test the model, online surveys among 2,332 consumers have been conducted in two countries. All respondents had experience with buying a house and choosing a mortgage. The respondents were randomly selected from the GfK-consumer panels in The United Kingdom and The Netherlands and divided into two groups: (1) 2013 The Netherlands ( $N=1407)$ and (2) 2013 The United Kingdom $(N=935)$. To design the model, these two front-running financial advice markets were selected. The UK and The Netherlands are being understood as front-runners because of theiradvanced financial advice eco-systems (financial advisors, governmental regulation, and FinTech industry). The first online survey was held in Q1 2013 in The Netherlands $(N=1407)$. The second survey was held in Q4 2013 in The United Kingdom $(N=935)$. The surveys were used to develop the DCX model. On the data, exploratory factor analysis was applied to design the best fitting model. Five dominant factors were obtained explaining customer satisfaction. With the factor scores as independent variables, multiple regression analysis was applied to explain customer satisfaction of the customer experience and to develop the digital customer experience model (DCX model).

\section{Developing a Conceptual Model and Survey Design}

Based on earlier research, field studies, and several brainstorms, the conceptual model has been developed (Figure 1). The variables that could potentially have impact on the customer experiences of digital financial advice systems are given in Table 1.

Based on the variablelist, a questionnaire was developed in close co-operation with research agency GfK. The questionnaire consisted of five lettered sections with 38 questions on satisfaction with attributes of the advisor and the advice service quality. The A-section contained screening questions to build a social-demographic profile of the respondents. The B-section contained questions on performance evaluation of recent mortgage closings. Respondents were asked to rank their experience with the performance on the variable list of their most important financial advisor. Scoring took place on a seven-point Likert-scale. The C-section contained questions for benefit evaluation on the variable list of mortgage closings. Again, scoring took place on a seven-point Likert-scale. The D- and E-section contained questions about the respondents' motivational profiles. The D- and E-section's results are used in another study on the customer motivations to use digital and robo-advice. The survey was validated on a pilot-group of 100 respondents prior to the larger online. 


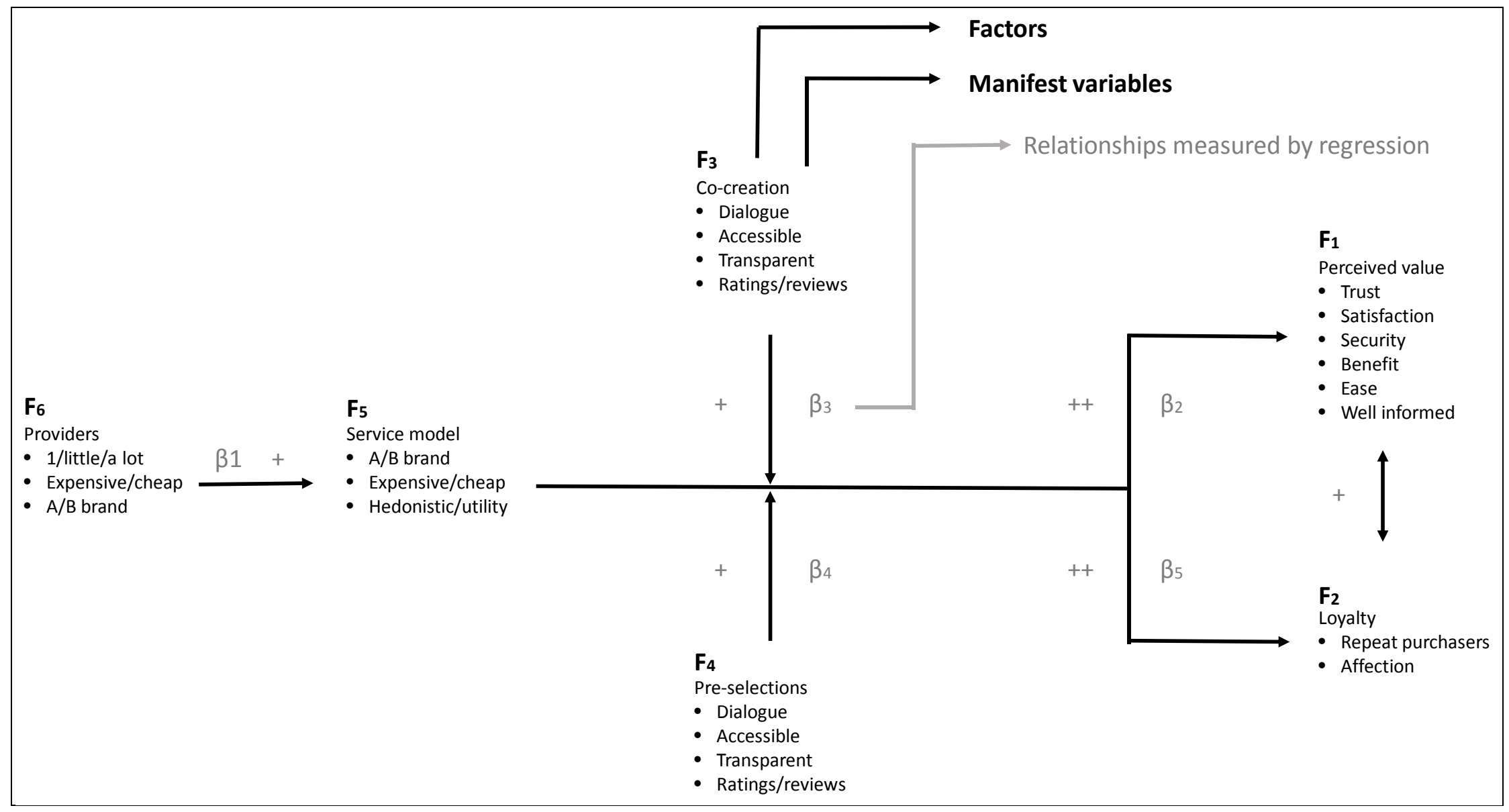

Figure 1. Conceptual model. 
Table 1

List of Variables

A good working relationship with the advisor

Accessibility-a location easy to get

Accuracy

Advice geared towards getting the lowest monthly cost (price)

Advice that matches personal situation

Advice with only your best interest at heart

Being able to arrange the mortgage through the advisor

Being able to get advice about mortgage related financial products

Being able to get advice about other financial products

Being given the feeling of being equal

Empathy

Expertise

Freedom to decide on the place and time of appointment

Friendliness

Helpfulness

Honesty

Honouring agreements

Independent advice

Methods to get in contact

Preference for a mortgage provider being taken into account in the advice

Preference for a type of mortgage being taken into account in the advice

Proactivity (providing useful information beyond what is asked)

Reliability

Reputation of the mortgage provider(s)

Room for negotiation

Size of the company giving advice

Speed of response

Taken into account the degree of risk willing to take

Time taken to give advice

Transparency of way of work

Usefulness of the advice

Using understandable language

Well-know (good reputation, references)

\# different types of compared mortgages

\# different type of mortgages to choose from

\# mortgage providers to choose from

\section{Experiments}

\section{DCX-Experiment 1, The Netherlands}

The first online survey was held in the first quarter of 2013 in The Netherlands with 1,407 respondents. The respondents were either experienced advice users $(N=815$; consumers who received mortgage advice in the last year) or inexperienced users ( $N=592$; consumers who had received mortgage advice longer than one year ago) to compensate for recency effects in defining the parameters of the model. The data were factor-analyzed to develop the DCX model. Principal component with varimax rotation was applied to develop 
the scores in the factor model. Factor scores were used in multiple regression analysis (Table 2) to explain customer experience. The model explains well with an $R$-square of 0.52 . Based on these outcomes, the DCXnl model developed (Figure 2).

Table 2

Factor Table NL

\begin{tabular}{|c|c|c|c|c|c|c|}
\hline & F1 & $\mathrm{F} 2$ & F3 & $\mathrm{F} 4$ & F5 & F6 \\
\hline & $\begin{array}{l}\text { Advising } \\
\text { Qualities }\end{array}$ & Pre-selection & Co-creation & $\begin{array}{l}\text { Advising } \\
\text { Style }\end{array}$ & Accessibility & Price \\
\hline Reliability & 0.69 & & & & & \\
\hline Accuracy & 0.69 & & & & & \\
\hline Expertise & 0.75 & & & & & \\
\hline Helpfulness & 0.66 & & & 0.45 & & \\
\hline Friendliness & 0.66 & & & & & \\
\hline Honesty & 0.71 & & & & & \\
\hline “click” & 0.63 & & & & & \\
\hline Understandable & 0.63 & & & & & \\
\hline Independent & 0.62 & 0.42 & & & & \\
\hline "best interest" & 0.60 & 0.41 & & & & \\
\hline “personal match” & 0.69 & & & & & \\
\hline Empathy & 0.71 & & & & & \\
\hline Proacitveness & 0.69 & & & & & \\
\hline Monthly costs & 0.67 & & & & & \\
\hline Usefulness & 0.71 & & & & & \\
\hline Time taken & 0.52 & & & 0.59 & & \\
\hline Transparency & 0.58 & & & & & \\
\hline Advisors rate & & & & & & 0.75 \\
\hline Contact possibilities & 0.44 & & & 0.64 & & \\
\hline Response rate & 0.46 & & & 0.71 & & \\
\hline Availability & & & & & 0.77 & \\
\hline Freedom to meet & & & & 0.55 & & \\
\hline Reknown & 0.50 & & & & 0.43 & \\
\hline Company size & 0.43 & & & & 0.48 & \\
\hline Closing process & 0.62 & & & 0.47 & & \\
\hline Honouring agreements & 0.61 & & & 0.55 & & \\
\hline Broad offering brands & & 0.78 & & & & \\
\hline Reputation offering & & 0.72 & & & & \\
\hline Broad offering types & & 0.73 & & & & \\
\hline Broadness compared & & 0.67 & & & & \\
\hline Clarity conditions & 0.49 & 0.56 & & & & \\
\hline Possibility other advice & & 0.71 & & & & \\
\hline Possibility non-mortgage & & 0.72 & & & & \\
\hline Own brand wishes used & & & 0.69 & & & \\
\hline Own type wishes used & & & 0.68 & & & \\
\hline Equality in relation & 0.51 & & 0.64 & & & \\
\hline Negotiation space & & & 0.53 & & & \\
\hline Risk appetite & 0.40 & & 0.70 & & & \\
\hline
\end{tabular}

Note. Method: Principal Component Analysis with Varimax rotation. 


\begin{tabular}{|lll|}
\hline & & \\
$\mathrm{F}_{1}$ & Factors & Regression weights \\
$\mathrm{F}_{2}$ & Advising qualities & 0.77 \\
$\mathrm{~F}_{3}$ & Pre-selection & 0.31 \\
$\mathrm{~F}_{4}$ & Co-creation & 0.26 \\
$\mathrm{~F}_{5}$ & Advicsing style & 0.46 \\
$\mathrm{~F}_{6}$ & Accessibility & 0.14 \\
& Price & 0.21 \\
& Constant & 5.86 \\
& & $R^{2}=0.52$ \\
\hline
\end{tabular}

Figure 2. DCXnl factor model.

\section{DCX-Experiment 2, The United Kingdom}

The second online survey took place in the third quarter of 2013 in The United Kingdom and included 935 respondents. Because the distinction between experienced and inexperienced users in the first survey created no new insights, the respondents in this experiment were only experienced advice users (consumers who had received mortgage advice in the last year). To be able to compare the results over the studies, the same questionnaires and analysis were applied. To be able to compare across geographies, also in The United Kingdom principal component analysis with varimax rotation was applied (Table 3) and five factors were obtained. Factor scores were used in a multiple regression analysis (Table 3). The model explains even better than in The Netherlands with an $R$-square of 0.81 . Based on the results, the DCXuk model was developed (Figure 3).

Table 3

\section{Factor Table UK}

\begin{tabular}{|c|c|c|c|c|c|}
\hline & $\mathrm{F}_{1}$ & $\mathrm{~F}_{2}$ & $\mathrm{~F}_{3}$ & $\mathrm{~F}_{4}$ & $\mathrm{~F}_{5}$ \\
\hline & $\begin{array}{l}\text { Advising } \\
\text { qualities }\end{array}$ & $\begin{array}{l}\text { Proces } \\
\text { influence }\end{array}$ & $\begin{array}{l}\text { Advising } \\
\text { width }\end{array}$ & $\begin{array}{l}\text { Price } \\
\text { image }\end{array}$ & Accessibility \\
\hline Reliability & 0.79 & & & & \\
\hline Accuracy & 0.77 & & & & \\
\hline Expertise & 0.76 & & & & \\
\hline Helpfulness & 0.77 & & & & \\
\hline Friendliness & 0.66 & & & & \\
\hline Honesty & 0.75 & & & & \\
\hline A good working relationship with the advisor & 0.75 & & & & \\
\hline Using language you can understand & 0.57 & & & & \\
\hline Independent advice & 0.57 & & 0.51 & & \\
\hline Advice with only your best interests at heart & 0.71 & & & & \\
\hline $\begin{array}{l}\text { Advice that matches your personal situation (income, } \\
\text { education, family situation) }\end{array}$ & 0.66 & & & & \\
\hline Empathy (can empathize with my situation) & 0.63 & & & & \\
\hline $\begin{array}{l}\text { Proactivity (providing useful advice and information beyond } \\
\text { what you asked about) }\end{array}$ & 0.69 & & & & \\
\hline Advice geared towards getting the lowest monthy cost (price) & 0.62 & & & & \\
\hline Usefulness of the advice & 0.73 & & & & \\
\hline Time to taken to get to giving you advice & 0.75 & & & & \\
\hline Transparency of the way the advisor works & 0.74 & & & & \\
\hline
\end{tabular}


Table 3 continued

The cost of getting advice

How you can get in contact (telephone, mail, face to face)

Speed of response

Accessibility: a location that is easy for you to get to

Freedom to decide on the place and time of appointment yourself

Well-known (good reputation, references)

Size of the company that's giving advice

Being able to arrange the mortgage through the advisor

Honouring agreements

The number of mortgage providers from which you can choose

The reputation of the mortgage provider(s) from which you can choose

The number of different types of mortgage from which you can choose

The number of different types of mortgages that are compared

The clarity of the explanation of the mortgage terms and conditions

Being able to get advice about financial products that go with a mortgage

Being able to get advice about other financial products

My preference for a mortgage provider being taken into account in the advice

My preference for a type of mortgage being taken into account in the advice

Being given the feeling that I am unequal

Room for negotiation

0.45

0.65

0.74

0.53

0.46

0.69

0.75

\begin{tabular}{llll} 
& & 0.68 & \\
& 0.41 & & 0.51 \\
& 0.51 & 0.45 & 0.48 \\
0.45 & 0.51 & 0.45 & 0.44 \\
& & & 0.47 \\
& & 0.74 & \\
0.43 & 0.73 & 0.79 & \\
0.46 & 0.68 & & \\
& 0.68 & & \\
& 0.73 & & \\
\hline
\end{tabular}

0.56

0.44

Taking into account the degree of risk I am willing to take

Note. Method: Principal Component Analysis with Varimax rotation.

\begin{tabular}{|lll|}
\hline & & \\
$\mathrm{F}_{1}$ & Factors & Regression weights \\
$\mathrm{F}_{2}$ & Advising qualities & 0.71 \\
$\mathrm{~F}_{3}$ & Process influence & 0.32 \\
$\mathrm{~F}_{4}$ & Advising width & 0.23 \\
$\mathrm{~F}_{5}$ & Price image & 0.28 \\
& Accessibility & 0.09 \\
& Constant & 5.93 \\
& & $R^{2}=0.81$ \\
\hline
\end{tabular}

Figure 3. DCXuk factor model.

\section{The DCX Model and Its Validation in Two Markets}

\section{DCXnl Factor Model}

The surveys in The United Kingdom and The Netherlands point towardsimilar factors for customer experience in digital financial advice. This supports the explanation of the cross-cultural expectations of digital financial advice.

Based on the results of the first experiment in The Netherlands the DCXnl model has been developed (Figure 3). The DCXnl model differed from the conceptual model initially developed. The factors of the DCXnl 
model explain 52 percent of the variance (CX: $\left.R^{2}=0.52\right)$. If DCXnl (customer satisfaction with customer experience) is the dependent variable and advising qualities $\left(F_{1}\right)$, pre-selection $\left(F_{2}\right)$, co-creation $\left(F_{3}\right)$, advising style $\left(\mathrm{F}_{4}\right)$, accessibility $\left(\mathrm{F}_{5}\right)$, and price $\left(\mathrm{F}_{6}\right)$ are the independent variables, DCXnl can be defined as:

$$
\mathrm{DCXnl}=0.77 \mathrm{~F}_{1}+0.31 \mathrm{~F}_{2}+0.26 \mathrm{~F}_{3}+0.46 \mathrm{~F}_{4}+0.14 \mathrm{~F}_{5}+0.21 \mathrm{~F}_{6}+5.86
$$

\section{DCXuk Factor Model}

The second survey (UK) shows a DCX model that also differs from the initial conceptual model. The factors of the DCXuk model explain 81 percent of the variance (CX: $R^{2}=0.81$ ). If DCXuk (customer satisfaction with customer experience) is the dependent variable and advising qualities $\left(\mathrm{F}_{1}\right)$, process influence $\left(\mathrm{F}_{2}\right)$, advising width $\left(\mathrm{F}_{3}\right)$, priceimage $\left(\mathrm{F}_{4}\right)$, and accessibility $\left(\mathrm{F}_{5}\right)$ are the independent variables, DCXuk can be defined as:

$$
\text { DCXuk }=0.71 \mathrm{~F}_{1}+0.32 \mathrm{~F}_{2}+0.23 \mathrm{~F}_{3}+0.28 \mathrm{~F}_{4}+0.09 \mathrm{~F}_{5}+5.93
$$

\section{Hypothesis Testing for Model Integration}

As the regression formulas show the DCX model shows important similarities between the British and the Dutch market. In both markets, $\mathrm{F}_{1}$ (advising qualities) is a significant explanatoryfactor of customer experience. In the DCXnl, the factor score is 0.77 , whereas in the DCXuk the factor score is 0.71 . Both scores are significantly different from zero $(p<0.01)$. Therefore, the first hypothesis can be accepted.

$\mathrm{H}_{1}$ : Although people lack the knowledge to validate it, advice quality is a significant factor in explaining the customer satisfaction with digital financial advice.

To test the second hypothesis, the nature of the explanatory attributes for factor $\mathrm{F}_{1}$ advising quality has been assessed. The hypothesis covers the domain of how consumers assess the quality of financial advice. This is very hard to do without in-depth product knowledge. From Tables 2 and 3, it can be seen that the explanatory variables of advising quality $\left(\mathrm{F}_{1}\right)$ contain, as hypothesized, outcome, system, and process attributes.

Outcome-related attributes are the accuracy of the advice (0.77), match of the advice with personal situation(0.66), usefulness of the advice (0.73), honoring agreements (0.75) (UK), and usability (0.73).

Process-related attributes are reliability (0.79), helpfulness (0.77), good working relationship (0.75), honesty (0.75), friendliness (0.66), advice with the best interest at heart (0.71), empathy (0.63) (UK), and empathy (0.71) (NL).

System-related attributes are expertise (0.76), time taken to come to concluding advice (0.75), transparency (0.74) (UK), and expertise (0.76) (NL).

In relation to $\mathrm{F}_{1}$, advising quality, indeed outcome, process, and system attributes play an important role in the customer experience. In both markets, factor loadings of process and system related attributes are indeed slightly higher than the outcome-related factor loadings. In this respect, the UK also seems to have higher thresholds for the performance of digital advisors on customer satisfaction than the Dutch $(p<0.01)$. The attributes explaining their experience of $F_{1}$ advising quality are also more outcome-oriented and richer. All in all, $\mathrm{H}_{2}$ can not be rejected.

$\mathrm{H}_{2}$ : Because people find it is difficult to evaluate financial advice quality, both system-related aspects and process-related aspects of digital financial advice have impact on customer experiencejust as outcome-related aspectssuch as the advice quality.

To test the third hypothesis, the other factors in the DCX model and their attributes were assessed to 
discover experiential attributes. Looking at the names of the factors, one may get the impression that higher DCX scores can be obtained by improving functionality [process influence (UK: 0.26), advising width (UK: 0.19; NL: 0.22), and price (UK: 0.23; NL: 0.15)]. Nevertheless, as presented in the factor tables, except from outcome-related attributes such as theaccuracy of the advice (0.77), usability of the advice (0.71), advice width (UK: 0.19; NL: 0.22), size of the company (0.03), and price (UK: 0.23 ; NL: 0.15 ), all other attributes carry experiential value. Attributes such as honesty (UK: 0.75; NL: 0.71), friendliness (UK: 0.66; NL: 0.66), helpfulness (UK: 0.774; NL: 0.66), and empathy (UK: 0.63; NL: 0.71) play an important role in both markets. As expected with financial advice as a credence good, looking at the scores of the attributes, the experiential value of digital financial advice is important for choice satisfaction and customer engagement. Although financial institutions primarily invest in customer experience to increase product sales, DCX of financial advice shows many experiential attributes in both the UK and the Dutch market. The third hypothesis can therefore not be rejected. With the upcoming of unknown brands as robo-or digital advisors, the authors argue that because of the ill-differentiating outcome attributes in digital financial advice, experiential service attributes in digital environments will have increasingly differentiating power.

$\mathrm{H}_{3}$ : Although traditional financial institutions underinvested in customer experience, it is hypothesized that hedonic experiential aspects of the customer experience in digital financial advice models are just asimportant as functional aspects.

\section{Discussion}

The goal of this research is to provide a cross-cultural set of structurally related factors and their attributes that explain the customer experiences of digital financial advice systems. Customer experience and financial advice are ill-defined concepts, and lack well developed assessment methods and metrics. The influence of self-directedness on financial decision making increases because the Internet enables consumers to learn from the experiences of others and to gather product information. Therefore, it was the objective to develop a cross cultural model for validating the customer experiences of digital financial advice. In doing so, both objective and subjective system aspects were assessed. The newly developed DCX model is the first scholarly model that reveals the factors and attributes that drive customer experience toward digital financial advice models.

Earlier research of service quality, human-computer interaction, and customer experience concluded that it is important to match expected quality or experience with actual quality or experience. Most researchers stated that the priority is to balance functional outcome attributes with experiential attributes. In this research, the increasing importance of experiential attributes on the customer experience of digital financial advice systems was investigated. Process- and system-related attributes are also impacting customer experiences of these systems just as outcome-related attributes. This development is expected to push through over the upcoming five to 10 years, fundamentally changing the expectations customers have on the customer experience of their banks and (digital) financial advisors.

The managerial impact for financial retailers of this development is in developing experience systems that bring services to the user that make financial decision making more reliable, accurate, helpful, and honest. Customers expect professional co-creation functionalities, support, and a broad product offering to result in the best perceived personalized services on top of the functional internet banking and advice systems. The DCX model can support the design and performance monitoring of these service systems. It also provides a foundation for better differentiation of advice brands and advice systems. 
Regulators supervise financial advice, primarily in a functional way. In their regulation and guidelines, the focus is mainly on the process of advice systems. In their control of advisory paper trails, they focus on the extent to which advisors gather the right information to base their product advice upon. With the DCX score, regulators can broaden their supervision from process-focused to system, outcome, and process approaches. This research shows that it is the combination of the three that determines the customer experience. Regulators may apply the DCX scores to compare the market performance on these respective items.

As banks, financial advisors, robo-advisors, and regulators are more focused on customer-centricity, it was the objective to support a better understanding of the customer experience of user-centric digital financial advice models. The developed DCX model is a validation instrument of the customer experience of digital financial advice brands. It can managerially help digital financial advisors to build deeper customer-centric advice relations and support regulators in broadening their supervision in this digital era.

\section{Looking Forward: Limitations and Future Research}

The DCX model may inspire researchers to further explore the customer experience of digital advice. As customer behavior becomes more self-directed, the expectations customers have from their experience of credence goods, such as financial advice, will be impacted. The application of the DCX model on different financial service markets such assmart budgeting, investing, small business lending, or financial planning will increase the quality of the DCX as a comparison instrument. However, the application of the DCX model on other credence goods markets, for example healthcare, mobile and internet communications, and automotive repair services, may help to improve the DCX model.

There are some limitations to this research that should be considered when interpreting findings. The new models are derived from research in the UK and Dutch markets. Although these markets are known as precursors in digital financial advice, additional geographic-specific research has to be conducted to generalize the findings to other global markets.

The data of this research were gathered in the year when both the UK and the Dutch governments introduced commission stops on complex financial advice. This stimulated the growth of online low cost financial advisors since 2013. Due to the short period between the introduction of the commission stop and the moment of this research, the price and accessibility benefits offered by these online financial advisors are still in its infancy. Additional time-series research should be performed to monitor the changing impact of the drivers in the DCX model and especially the price-elasticity of (digital) financial advice. In 2015, no difference was found in the factors and attributes described in this paper.

Finally, this research has been singularly performed on digital financial advice. Further research might be conducted to focused business models such as comparison sites, robo-advisors, and also advisors in other service industries like healthcare and utilities.

\section{References}

Alba, A., Lynch, J., Weitz, B., Janiszewski, C., Lutz, R., Sawyer, A., \& Wood, S. (1997). Interactive home shopping: Consumer, retailer, and manufacturer incentives to participate in electronic marketplaces. Journal of Marketing, 61, 38-53.

Bradbury, T. (2014). Robo-advice is coming: What it means, who will buy it-and why. Professional Planner, 69, 40.

Broderick, A. J., \& Vachirapornpuk, S. (2002). Service quality in internet banking: The importance of customer role. Marketing Intelligence \& Planning, 20, 327-335.

Collins, J. M. (2010). A review of financial advice models and the take-up of financial advice. Center for Financial Security WP 
10: 5 .

Cosley, D., Lam, S. K., Albert, I., Konstan, J. A., \& Riedl, J. (2003). Is seeing believing? How recommender system interfaces affect users' opinions. Proceedings of the SIGCHI conference on Human Factors in Computing Systems. ACM.

Cronin Jr, J. J., \& Taylor, S. A. (1992). Measuring service quality: A reexamination and extension. Journal of Marketing, 56, 55-68.

Dunbar, I. (2016). Robo-advice-Short term fad, or the future of financial advice? Equity.

Emons, W. (1997). Credence goods and fraudulent experts. The RAND Journal of Economics, 28, 107-119.

Frey, C. B., \& Osborne, M. (2015). Technology at work: The future of innovation and employment.

Gentile, C., Spiller, N., \& Noci, G. (2007). How to sustain the customer experience: An overview of experience components that co-create value with the customer. European Management Journal, 25, 395-410.

Grönroos, C. (1984). A service quality model and its marketing implications. European Journal of Marketing, 18, 36-44.

Herlocker, J. L., Konstan, J. A., \& Terveen, L. G. (2004). Evaluating collaborative filtering recommender systems. ACM Transactions on Information Systems, 22, 5-53.

Inderst, R., \& Ottaviani, M. (2012). Financial advice. Journal of Economic Literature, 50, 494-512.

Klein, L. R. (1998). Evaluating the potential of interactive media through a new lens: Search versus experience goods. Journal of Business Research, 41, 195-203.

Knijnenburg, B. P., \& Willemsen, M. C. (2009). Understanding the effect of adaptive preference elicitation methods on user satisfaction of a recommender system. Proceedings of The Third ACM Conference on Recommender Systems. ACM.

Knijnenburg, B. P., Willemsen, M. C., \& Hirtbach, S. (2010). Receiving recommendations and providing feedback: The user-experience of a recommender system. E-Commerce and web technologies (pp. 207-216). Berlin Heidelberg: Springer.

Knijnenburg, B. P., Willemsen, M. C., \& Kobsa, A. (2011). A pragmatic procedure to support the user-centric evaluation of recommender systems. Proceedings of The Fifth ACM Conference on Recommender Systems. ACM.

Knijnenburg, B. P., Willemsen, M. C., Ganter, Z., Soncu, H., \& Newell, C. (2012). Explaining the user experience of recommender systems. User Modeling and User-Adapted Interaction, 22, 441-504.

Komiak, S. Y. X., \& Benbasat, I. (2006). The effects of personalization and familiarity on trust and adoption of recommendation agents. Mis Quarterly, 30, 941-960.

Konstan, J. A., \& Riedl, J. (2012). Recommender systems: From algorithms to user experience. User Modeling and User-Adapted Interaction, 22, 101-123.

Koren, Y. (2010). Collaborative filtering with temporal dynamics. Communications of the ACM, 53(4), 89-97.

Koren, Y., Bell, R., \& Volinsky, C. (2009). Matrix factorization techniques for recommender systems. Computer, 8, 30-37.

L’Hostis, A., \& Ensor, B. (2015). Follow best practices to encourage mobile banking use. Forrester.

Lynch Jr, J. G., \& Ariely, D. (2000). Wine online: Search costs affect competition on price, quality, and distribution. Marketing Science, 19, 83-103.

Malhotra, R., \& Malhotra, D. K. (2006). The impact of internet and e-commerce on the evolving business models in the financial services industry. International Journal of Electronic Business, 4(1), 56-82.

McNee, S. M., Riedl, J., \& Konstan, J. A. (2006). Making recommendations better: An analytic model for human-recommender interaction. CHI'06 extended abstracts on Human factors in Computing Systems. ACM, 2006.

Meyer, C., \& Schwager, A. (2007). Understanding customer experience. Harvard Business Review, 85, 116-126.

Murray, K. B., \& Haubl, G. (2009). Personalization without interrogation: Towards more effective interactions between consumers and feature-based recommendation agents. Journal of Interactive Marketing, 23, 138-146.

Nelson, P. (1970). Information and consumer behavior. Journal of Political Economy, 78, 311-329.

Ozok, A. A., Fan, Q., \& Norcio, A. F. (2010). Design guidelines for effective recommender system interfaces based on a usability criteria conceptual model: Results from a college student population. Behaviour \& Information Technology, 29, 57-83.

Parasuraman, A., Berry, L. L., \& Zeithaml, V. A. (1991). Refinement and reassessment of the SERVQUAL scale. Journal of Retailing, 67, 420-450.

Parasuraman, A., Zeithaml, V. A., \& Berry, L. L. (1985). A conceptual model of service quality and its implications for future research. Journal of Marketing, 49, 41-50.

Parasuraman, A., Zeithaml, V. A., \& Berry, L. L. (1994). Reassessment of expectations as a comparison standard in measuring service quality: Implications for further research. Journal of Marketing, 58, 111-124.

Peterson, R. A., Balasubramanian, S., \& Bronnenberg, B. J. (1997). Exploring the implications of the Internet for consumer marketing. Journal of the Academy of Marketing Science, 25, 329-346. 
Pu, P., Chen, L., \& Hu, R. (2012). Evaluating recommender systems from the user's perspective: Survey of the state of the art. User Modeling and User-Adapted Interaction, 22, 317-355.

Santos, J. (2003). E-service quality: A model of virtual service quality dimensions. Managing Service Quality: An International Journal, 13(3), 233-246.

Seth, N., Deshmukh, S. G., \& Vrat, P. (2005). Service quality models: A review. International Journal of Quality \& Reliability Management, 22, 913-949.

Stigler, G. J. (1961). The economics of information. Journal of Political Economy, 69, 213-225.

Teltzrow, M., \& Kobsa, A. (2004). Impacts of user privacy preferences on personalized systems. Designing personalized user experiences in ecommerce (pp. 315-332). Netherlands: Springer.

Van Raaij, W. F. (2016). Understanding consumer financial behavior. Money management in an age of financial illiteracy. New York: Palgrave Macmillan.

Van Thiel, D. (2009). Got EQ? Cool! The fast track for future marketing winners. Amsterdam: Pearson Financial Times Prentice Hall.

Van Thiel, D., Goedee, J., \& Reijnders, W. (2008). Riding the waves. The future of banking starts now. Amsterdam: Pearson Financial Times Prentice Hall.

Verhoef, P. C., Lemon, K. N., Parasuraman, A., Roggeveen, A., Tsiros, M., \& Schlesinger, L. A. (2009). Customer experience creation: Determinants, dynamics and management strategies. Journal of Retailing, 85, 31-41.

Wolinsky, A. (1995). Competition in markets for credence goods. Journal of Institutional and Theoretical Economics (Zeitschrift für die gesamte Staatswissenschaft), 151, 117-131. 